\title{
Identificação de princípios ativos presentes na Ipomoea carnea brasileira
}

\author{
Aline Schwarz ${ }^{1}$, Rosana Zoriki Hosomi², Breno Schumaher Henrique', Isis Hueza ${ }^{2}$, \\ Dale Gardner ${ }^{3}$, Mitsue Haraguchi ${ }^{4}$, Silvana Lima Górniak², Maria Martha Bernardi², \\ Helenice de Souza Spinosa ${ }^{2 *}$
}

\begin{abstract}
${ }^{1}$ Departamento de Toxicologia e Análises Toxicológicas, Faculdade de Ciências Farmacêuticas, Universidade de São Paulo, ${ }^{2}$ Departamento de Patologia, Faculdade de Medicina Veterinária e Zootecnia, Universidade de São Paulo, ${ }^{3}$ USDA-ARS Poisonous Plants Research Laboratory, Utah State Universit, ${ }^{4}$ Centro de Sanidade Animal, Instituto Biológico de São Paulo
\end{abstract}

*Correspondência:

H. S. Spinosa

Faculdade de Medicina Veterinária e Zootecnia - USP

Av. Prof. Dr. Orlando Marques de Paiva, 87

05508-900 São Paulo - SP - Brasil

E-mail: hspinosa@usp.br
Dentre as espécies pertencentes à família das Convolvulaceae destacam-se as Ipomoeas, amplamente distribuidas por todo o mundo, bastante conhecidas e cultivadas devido ao aspecto ornamental que suas flores campanuladas e de cores vibrantes oferecem. É sabido porém que espécies de Ipomoeas são tóxicas. A Ipomoea carnea, espécie de nosso estudo, provoca emagrecimento, apatia, incoordenção motora, fraqueza progressiva $e$ até mesmo a morte em animais de produção, se ingerida por período prolongado. Os alcalóides suainsonina e calisteginas presentes nesta planta são certamente responsáveis por tais efeitos tóxicos, já que inibem a ação das manosidases e glicosidases, enzimas fundamentais para um adequado metabolismo de carboidratos pelo organismo. O presente trabalho teve como objetivo verificar e caracterizar os constituintes químicos da I. carnea brasileira. Assim, empregando-se as cromatografias de camada delgada e líquida acoplada a detector de massas, além da ressonância nuclear de prótons e carbono, foram detectados no extrato aquoso obtido das folhas da planta, 0,09\% de suainsonina, $0,11 \%$ de calistegina $B_{2}, 0,14 \%$ de calistegina $B_{1,}, 0,06 \%$ de calistegina $C_{1}$ e o aminoácido não protéico $\mathrm{N}$-metil-trans-4-hidroxiL-prolina.
Unitermos

- Ipomoea carnea

- Suainsonin

- Calisteginas

- Cromatografia

\section{INTRODUÇÃO}

A Ipomoea carnea Jacq. subsp. Fistulosa (Mart.) Choisy (anteriormente denominada Ipomoea fistulosa Mart. ex Choisy, I. gossypioides Parodi, I. texana Coulter), pertencente à família das Convolvulaceae, é uma planta arbustiva, leitosa, pouco ramificada, de caules ocos, (Lorenzi, 1991). Esta planta propaga-se rapidamente, inclusive em condições climáticas adversas, devido à sua resistência às secas (Tirkey et al., 1987), sendo, portanto, encontrada em diversas regiões do Brasil, onde é conhecida popularmente como canudo, algodão-bravo, mata-cabra, campainha, algodão- 
do-pantanal, algodão-do-brejo, canudo-de-lagoa, mata-pinto, salsa-branca, campainha-de-canudo, capa-bode (Lorenzi, 1991; Tokarnia et al., 2000).

Há relatos, no Brasil, de intoxicação de animais de produção que ingeriram a I. carnea em condições naturais. Assim, Tokarnia et al. (1960) observaram série de sinais clínicos após exposição prolongada ad libitum à I. carnea em bovinos, ovinos e caprinos. Os bovinos apresentaram emagrecimento, apatia, pêlo áspero e fraqueza. Os ovinos desenvolveram fraqueza, apatia, perda de apetite após períodos variáveis da ingestão da planta. A espécie caprina foi a que apresentou os sinais mais evidentes da intoxicação por I. carnea, caracterizado por: apatia, incoordenação motora, paresia dos membros pélvicos, fraqueza progressiva e, por fim, a morte.

Recentemente, Schumaher-Henrique et al. (2003) observaram que cabras expostas por período prolongado à I. carnea desenvolveram ingestão compulsiva pela planta e quadro clínico semelhante àquele acima descrito, além de alterações hematológicas e histopatológicas.

A I. carnea possui os alcalóides suainsonina e calesteginas como principais princípios ativos e, certamente, responsáveis pelos efeitos tóxicos da mesma (De Balogh et al., 1999; Schwarz et al., 2003).

A suainsonina - 1,2,8-tri-hidroxi-octo-hidroindolizidina - é um alcalóide indolizidínico, potente inibidor da $\alpha$-manosidase lisossômica e $\alpha$-manosidase II do complexo de Golgi. A inibição da $\alpha$-manosidase lisossômica provoca acúmulo de oligossacarídeos não processados adequadamente em lisossomos e perda da função celular seguida de morte da célula. A inibição da $\alpha$-manosidase II provoca alterações na síntese, no processamento e no transporte de glicoproteínas, resultando em disfunção na adesão celular à moléculas, hormônios e vários receptores de membrana. A união destes efeitos resulta na constatação clínica de alterações endócrinas, reprodutivas, imunes, embriogenéticas e gastrintestinais (Stegelmeier et al., 1995), além de toda a sintomatologia anteriormente descrita.

A inibição destas duas enzimas pela suainsonina ocorre de forma competitiva, porém, em concentrações mais elevadas $(1 \mathrm{mM})$, este alcalóide inibe também a aglicosidase, $\beta$-glicuronidase, $\beta$-galactosidase, $\beta$ xilosidase e $\alpha$-arabinosidase (Cenci Di Bello et al., 1989).

As calisteginas são alcalóides nortropânicos poliidroxilados amplamente distribuídos nas espécies pertencentes às famílias Solanaceae e Convolvulaceae (Watson et al., 2001). Os membros conhecidos desta nova classe de alcalóides foram subdivididos em três grupos de acordo com o número de hidroxilas presentes em sua estrutura: calisteginas A (com três grupos hidroxila), B (com quatro grupos) e C (com cinco grupos) (Asano et al., 2001).
As calisteginas possuem também atividade inibitória sobre as enzimas $\beta$-glicosidase, $\alpha$ - e $\beta$-galactosidase e $\beta$ xilosidase, pois possuem estrutura semelhante à de carboidratos (Asano et al., 1997). Esta inibição competitiva em relação às glicosidases explica a afinidade existente entre as calisteginas e os alcalóides indolizidínicos, como a suainsonina, exacerbando, quando presentes numa mesma planta, a ação tóxica desta última (Watson et al., 2001).

Esta interessante capacidade de inibir glicosidases e manosidases faz da suainsonina e calisteginas importantes ferramentas em estudos de agentes anticancerígenos, antitumores-proliferativos, antimetastáticos (Nemr, 2001), uma vez que o catabolismo e processamento de glicoproteínas pelas glicosidases envolve a transformação de células normais à células cancerígenas. Portanto, em concentrações baixas, estes alcalóides inibem a ação destas enzimas, impedindo a formação destas patologias sem acarretar efeitos tóxicos (Watson et al., 2001).

Tirkey et al. (1988) ao realizar estudo fitoquímico com os extratos da I. carnea encontrou alcalóides tanto no extrato aquoso como no etéreo, sendo que glicosídeos e taninos também estavam presentes, porém apenas no extrato aquoso da planta. De Balogh et al. (1999) detectaram, na I. carnea de Moçambique, além da suainsonina, as calisteginas $\mathrm{B}_{2}$ e $\mathrm{C}_{1}$ Asano et al. (2000) em estudo com a mesma planta observaram, ainda, calistegina $\mathrm{B}_{1}$ e o alcalóide $2 \alpha-7 \beta$-diidroxinortropano, já anteriormente isolado de seis espécies de plantas da família das Convolvulaceae, como constituintes da I. carnea.

O objetivo do presente estudo foi detectar e caracterizar os constituintes químicos da I. carnea brasileira, uma vez que esta planta pode ser consumida pelos animais de produção, acarretando prejuizos econômicos na pecuária nacional, além de poder ser fonte destes alcalóides empregados como ferramentas no estudo de agentes anticancerígenos.

\section{MATERIAL E MÉTODOS}

\section{Planta}

A identificação da I. carnea foi realizada pela taxonomista Rosângela Simão Bianchini, do Instituto de Botânica de São Paulo. O plantio da I. carnea foi realizado por estaqueamento em uma área de aproximadamente $1.500 \mathrm{~m}^{2}$ de terreno no Centro de Pesquisa em Toxicologia Veterinária (CEPTOX) localizado em Pirassununga-SP. Após o crescimento da planta, as folhas foram colhidas, retirados seus pecíolos, acondicionadas a vácuo em sacos plásticos, congeladas e encaminhadas à cidade de São Paulo em recipientes de isopor adequadamente vedados. 
Em São Paulo, as folhas foram mantidas congeladas em freezer $-20^{\circ} \mathrm{C}$, no Laboratório de Toxicologia do Departamento de Patologia da Faculdade de Medicina Veterinária da Universidade de São Paulo, para posterior extração dos princípios ativos.

\section{Extração dos princípios ativos das folhas frescas da Ipomoea carnea}

O procedimento de extração foi baseado naquele descrito por Tulsiani et al. (1984). Assim, as folhas frescas da planta foram trituradas com etanol $97^{\circ} \mathrm{GL}$ em liquidificador. A seguir, foram maceradas por 72 horas e, após este período, filtradas em gaze. O filtrado foi submetido a concentração parcial em rotaevaporador, sob pressão reduzida à temperatura de $50^{\circ} \mathrm{C}$, até a eliminação do etanol. O solvente recuperado foi novamente adicionado às mesmas folhas trituradas e submetidas à maceração por mais 24 horas, sendo, a seguir, filtrado e evaporado, como descrito anteriormente. Este procedimento foi repetido novamente, por mais duas vezes, num total de quatro extrações. Os extratos obtidos foram reunidos formando o extrato hidroalcoólico. Este foi filtrado em papel de filtro pregueado e assim obtidas duas novas frações: fração insolúvel em água (FIA) e fração solúvel em água (FSA). A FSA foi submetida a partição com butanol saturado em água para fornecer duas porções: fração butanólica e fração aquosa. A fração butanólica foi concentrada totalmente através do rotaevaporador, dando origem ao resíduo butanólico e, por sua vez, a fração aquosa foi evaporada parcialmente, fornecendo a fração aquosa final.

Parte desta fração foi precipitada com etanol absoluto exaustivamente e, em seguida, filtrada. Obtiveram-se duas porções: o precipitado (PPT) e o filtrado. O filtrado foi evaporado para eliminação do solvente, obtendo-se a porção não-precipitada (NPPT). Alíquotas de $100 \mathrm{~mL}$ da fração NPPT foram fracionadas numa coluna de vidro $(12 \times 480$ $\mathrm{mm}$ ), contendo resina de troca iônica (AG 50W-X8 (forma $\mathrm{NH}^{+}$) catiônica) eluída com solução amoniacal 0,5\%. Foram coletadas 40 frações de $10 \mathrm{~mL}$ que, posteriormente, foram liofilizadas. A monitoração de cada fração foi realizada através de cromatografia de camada delgada (CCD).

\section{Caracterização dos alcalóides}

A caracterização dos alcalóides foi primeiramente realizada por cromatografia de camada delgada $(\mathrm{CCD}) \mathrm{em}$ sílica-gel G60, desenvolvida no sistema de solventes constituído de clorofórmio, metanol, hidróxido de amônio e água (35:13:1:1) com as frações obtidas da cromatografia de troca iônica. Para a revelação foram empregados anidrido acético e os reagentes de Erlich modificado e Dragendorff, de acordo com Tulsiani et al. (1984), com pequenas modificações. Em seguida, estas mesmas frações foram submetidas à espectroscopia de ressonância magnética nuclear de prótons e carbono 13 (RMN de $\mathrm{H}^{1}$ e $\mathrm{RMN}$ de $\mathrm{C}^{13}$ ) para identificação estrutural, na Central Analítica do Instituto de Química da Universidade de São Paulo, e seus espectros foram analisados.

Porções da fração aquosa final foram encaminhadas ao laboratório do Professor Dr. Dale Gardner do Utah State University (USDA-ARS Poisonous Plants Research Laboratory-EUA), onde foram analisadas quantitativamente por cromatografia líquida (LC) acoplada a espectrômetro de massas (EM), como descrito a seguir.

Extração das amostras: Alíquotas de $50 \mathrm{mg}$ da fração aquosa final foram acondicionadas em tubos de vidro de $15 \mathrm{~mL}$. Aos tubos foram adicionados $4 \mathrm{~mL}$ de clorofórmio e $5 \mathrm{~mL}$ de ácido acético glacial $2 \%$. Agitação mecânica e contínua foi aplicada por 16 horas, seguida de centrifugação (5 minutos) e separação das camadas de solventes da camada de resíduos da planta. A camada superficial de ácido acético foi removida e adicionada a uma coluna de vidro preenchida com resina catiônica Dowex 50 WX8-100. A resina e a solução foram então agitadas por rotação mecânica durante 15 minutos, permitindo a ligação dos cátions de alcalóides à resina. Após centrifugação das colunas, a solução ácida foi retirada e as colunas reservadas. Novamente, adicionaram-se $5 \mathrm{~mL}$ de ácido acético glacial $2 \%$ à mistura de fração aquosa e clorofórmio e novas amostras foram então extraídas após agitação mecânica (15 minutos) dos tubos. Estas amostras foram centrifugadas e as camadas de ácido acético, separadas e adicionadas às colunas de vidro reservadas. Por fim, as colunas foram lavadas por duas vezes consecutivas com água destilada, centrifugadas e a porção líquida descartada. Para a remoção dos alcalóides poliidroxilados da resina, $5 \mathrm{~mL}$ de hidróxido de amônio $1 \mathrm{M}$ foram adicionados nas colunas e estas agitadas mecanicamente (15 minutos). A seguir, as amostras foram retiradas e centrifugadas (1 minuto). As amostras aquosas de hidróxido de amônio obtidas foram removidas, acondicionadas devidamente e mantidas a $-20{ }^{\circ} \mathrm{C}$ até o momento da análise.

Análise de suainsonina e calisteginas: Para a detecção dos alcalóides poliidroxilados, alíquotas de $0,1 \mathrm{~mL}$ do extrato preparado foram evaporadas sob fluxo de nitrogênio a $70{ }^{\circ} \mathrm{C}$. A seguir foram derivatizadas por adição de $0,2 \mathrm{~mL}$ de piridina e $0,05 \mathrm{~mL}$ de trimetilsililtrifluoroacetamida (BSTFA) e aquecidas a $70^{\circ} \mathrm{C}$, por $30 \mathrm{mi}-$ nutos. Após a derivação foi realizada análise por CG-EM Finnigan GCQ com coluna capilar (30 m x 0,25 mm) J\&W DB-5MS das amostras. Hélio foi empregado como 
gás de arraste sob fluxo de $40 \mathrm{~cm} / \mathrm{s}$. A injeção das amostras $(2 \mathrm{~mL})$ foi feita no modo splitless com injetor a $255^{\circ} \mathrm{C}$. A temperatura da coluna foi programada para atingir $120{ }^{\circ} \mathrm{C}$ em 1 minuto, em seguida variar de $120{ }^{\circ} \mathrm{C}$ a $200{ }^{\circ} \mathrm{C}$ em 5 minutos, de $200{ }^{\circ} \mathrm{C}$ a $300{ }^{\circ} \mathrm{C}$ em 20 minutos e, por fim, permanecer a $300{ }^{\circ} \mathrm{C}$ por 8 minutos, respectivamente. A suainsonina e calisteginas foram identificadas por comparação dos tempos de retenção relativos e espectros de massas obtidos por Gardner et. al. (2001), Haraguchi et al. 2003, Molyneux et. al. (1993) e Molyneux et al. (2002). Para deterrminação quantitativa de suainsonina e calisteginas, uma segunda alíquota de $0,1 \mathrm{~mL}$ foi analizada por LC/MS, como descrito anteriormente (Dale et al., 2001). O sistema consistiu de bomba binária de solventes e autosampler HP-1100, coluna de fase reversa Betasil C18 (100 mm x $2 \mathrm{~mm}$ ) (Keystone Scientific) e espectrômetro de massas Finnigan LCQ. A suainsonina foi eluída através de método isocrático constituído de $5 \%$ de metanol em 20 $\mathrm{mM}$ de acetato de amônio sob fluxo de $0,5 \mathrm{~mL} / \mathrm{min}$. O volume de amostra injetado foi de $20 \mathrm{~mL}$. A ionização se deu através de fonte de ionização química por pressão atmosférica com temperatura de vaporização a $450{ }^{\circ} \mathrm{C}$ e descarga de $5 \mathrm{~mA}$ na corona. A temperatura capilar foi de $200{ }^{\circ} \mathrm{C}$ e voltagem de $16 \mathrm{~V}$. O espectrômetro de massas correu no modo $\mathrm{EM}^{2}$, a janela de observação foi estipulada entre 70 e 300 u.m.a., após fragmentação de molécula de suainsonina protonada ( $\mathrm{MH}+=174,2 \pm 0,75$ u.m.a.), por emprego de energia de colisão relativa a $25 \%$. O tempo máximo de injeção do tipo "íon trap" foi de $500 \mathrm{~ms}$. O tempo de retenção da suainsonina na coluna foi aproximadamente 1,4 minuto. A área do pico foi medida a partir do cromatograma $(m / z=156)$ e a quantificação baseada em padrão de calibração externo.

\section{RESULTADOS}

A cromatografia de troca iônica revelou componentes alcaloídicos de natureza cristalina e branca nas frações 20 a 33. A CCD foi então empregada nestas frações. Uma mancha de coloração clara no fundo amarelado após revelação com Dragendorff foi observada, indicando a presença de, pelo menos, um composto. Sabe-se, porém, que não se tratam de alcalóides pelo fato de que componentes alcaloídicos coram-se de laranja ou cores de tom aproximado quando na presença deste revelador. Por esta razão, este resíduo branco, proveniente destas porções, foi submetido à ressonância magnética nuclear não revelando sinais de prótons e de carbonos semelhantes aos dos alcalóides em estudo (suainsonina e calisteginas $\mathrm{B}_{2} \mathrm{e} \mathrm{C}_{1}$ ). $\mathrm{O}$ espectro obtido se sobrepôs ao do iminoácido não protéico $N$-metil-trans-4-hidroxi-L-prolina, isolado das folhas da Copaifera multijuga (Caesalpinioideae), e a rotação do iminoácido do presente estudo mostrou-se similar ao da literatura (Figliuolo et al., 1987).

Devido à não-caracterização dos alcalóides em estudo pela ressonância magnética nuclear, porções da fração aquosa final foram analisadas por LC-MS. Foram, então, detectadas e quantificadas na fração aquosa das folhas da planta, comparando-se com os padrões disponíveis, as seguintes substâncias: 0,09\% de suainsonina, $0,11 \%$ de calistegina $\mathrm{B}_{2}, 0,14 \%$ de calistegina $\mathrm{B}_{1}$ e $0,06 \%$ de calistegina $\mathrm{C}_{1}$, conforme mostrado na Figura 1.

\section{DISCUSSÃO}

A I. carnea vem sendo extensivamente estudada e seus componentes (alcalóides poliidroxilados) identificados quali- e quantitativamente por atuarem inibindo a função de enzimas participantes do complexo metabolismo dos carboidratos. Das folhas da I. carnea de Moçambique somente a suainsonina ( $31 \%)$ e as calisteginas $\mathrm{B}_{2}(50 \%)$ e $\mathrm{C}_{1}$ $(7 \%)$ foram detectadas através de cromatografia gasosa e espectrômetro de massas (De Balogh et al., 1999). Asano et al. (2001) detectaram por cromatografia de camada delgada e espectrômetro de massas a calistegina $\mathrm{B}_{1}(39 \mathrm{mg})$ e o composto $2 \alpha-7 \beta$-diidroxinortropano $(20 \mathrm{mg})$, além da suainsonina ( $86 \mathrm{mg}$ ) e da calistegina $\mathrm{B}_{2}(146 \mathrm{mg})$, nas folhas da I. carnea cultivada em herbário no Japão. Haraguchi et al. (2003) detectaram, além destes alcalóides anteriormente relatados, as calisteginas $\mathrm{B}_{1}$ e $\mathrm{B}_{3}$ e o iminoácido $N$-metiltrans-4-hidroxi-L-prolina como constituintes da I. carnea brasileira. No presente estudo constatou-se, por LC-MS, a presença dos alcalóides suainsonina $(0,09 \%)$ e calisteginas $\mathrm{B}_{1}(0,14 \%), \mathrm{B}_{2}(0,11 \%)$ e $\mathrm{C}_{1}(0,06 \%)$ e da calistegina $\mathrm{C}_{2}$ (traços) até então não detectada nesta planta. Por ressonância magnética nuclear os componentes alcaloídicos não foram constatados, mas sim o iminoácido não-protéico $N$-metiltrans-4-hidroxi-L-prolina.

Estudos anteriores realizados em nosso laboratório mostraram que a mesma I. carnea brasileira analisada no presente estudo foi capaz de provocar efeitos tóxicos em cabras (Schumaher-Henrique et al., 2003) e na prole de ratas exposta à planta durante a gestação (Schwarz et al., 2003). Estes efeitos tóxicos podem ser atribuidos à presença dos alcalóides poliidroxilados detectados nesta planta, que, quando ingerida por animais de produção, pode acarretar prejuízos econômicos na pecuária, uma vez que a $I$. carnea pode ser consumida em condições de campo. Ainda não se sabe quanto à possibilidade do iminoácido não protéico $N$-metil-trans-4-hidroxi-L-prolina ser ou não tóxico e, portanto, de sua contribuição no quadro clínico resultante da intoxicação pela ingestão da I. carnea. 


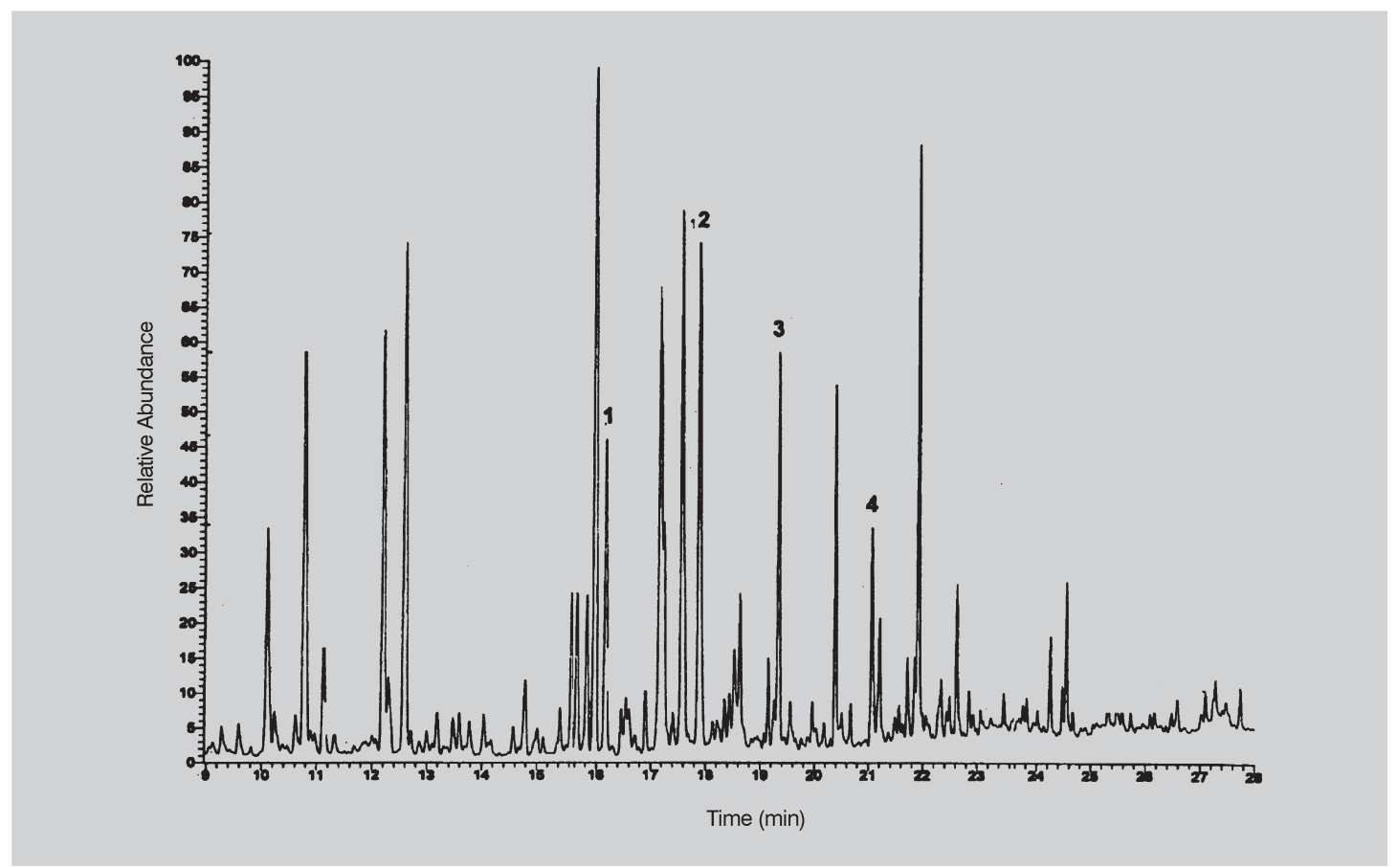

FIGURA 1 - Cromatograma da fração aquosa final da Ipomoea carnea por LC-EM (1- suainsonina, 2- calistegina $\mathrm{B}_{1}$, 3- calistegina $\mathrm{B}_{2}$ e 4- calistegina $\mathrm{C}_{1}$ ).

Vale ressaltar, ainda, que os alcalóides presentes na I. carnea podem ser empregados também como ferramentas para o estudo de agentes anticancerígenos. Neste sentido, Watson et al. (2001) relataram que a suainsonina inibiu o crescimento de células cancerosas e a disseminação destas células pelo organismo, mesmo quando empregada em concentrações muito baixas.

\section{AGRADECIMENTOS}

Este trabalho foi financiado pela Fundação de Amparo à Pesquisa do Estado de São Paulo (FAPESP) e é parte das dissertações de Mestrado apresentadas por Aline Schwarz à Faculdade de Ciências Farmacêuticas da Universidade de São Paulo e por Rosana Zoriki Hosomi ao Instituto de Ciências Biomédicas da Universidade de São Paulo.

\section{ABSTRACT}

\section{Identification of Brazilian Ipomoea carnea toxic compounds}

In the Convolvulaceae family, the Ipomoeas species are cultivated and found in all regions of the world because of their ornamental bright coloured flowers. It is well known that some Ipomoeas species are toxic. Ipomoea carnea, species of this study, causes depression, general weakness, loss of body weight, stagering gait and death of animals after prolonged periods of plant intake. These toxic effects are attributed to the alkaloids swainsonine and calystegines present in the plant, wich promotes inhibition of galactosidases and manosidases, important enzymes for an adequate metabolism of carbohydrates in the organism. The objective of the present study was to detect and characterize the chemical components of the Brazillian plant. For that, thin layer chromatography, high pressure liquid chromatography coupled to mass spectrometry detector and nuclear ressonance of protons and carbon were used. The aqueous extract of $\mathrm{I}$. carnea presented $0.09 \%$ swainsonine, $0.11 \%$ calystegine $B_{2}$, $0.14 \%$ of calystegine $B_{1}, 0.06 \%$ calystegine $C_{1}$ and the no proteic imino acid N-methyl-trans-4-hydroxy-L-proline.

UNITERMS: Ipomoea carnea. Swainsonine. Calystegines. HPLC/MS.

\section{REFERÊNCIAS BIBLIOGRÁFICAS}

ASANO, N.; KATO, A.; KIZU, H.; MATSUI, K.; GRIFFITHS, R. C.; JONES, M. G.; WATSON, A. A.; NASH, R. J. Enzymatic synthesis of the glycosides of calystegines $\mathrm{B}_{1}$ and $\mathrm{B}_{2}$ and their glycosidase inhibitory activities. Carbohydr. Res., v. 304, p. 173-178, 1997. 
ASANO, N.; NASH, R. J.; MOLYNEUX, R. J.; FLEET, G. W. J. Sugar-mimic glicosidase inhibitors: natural occurrence, biological activity and prospects for therapeutic application. Tetrahedron: Assymetry, v. 11, p. 1645-1680, 2000.

ASANO, N.; YOKOYAMA, K.; SAKURAI, M.; IKEDA, K.; KIZU, H.; KATO, A.; ARISAWA, M.; HOKE, D.; DRÄGER, B.; WATSON, A. A.; NASH, R. J. Dihydroxynortropane alkaloids from calystegineproducing plants. Phytochemistry, v. 57, p. 721-726, 2001.

CENCI DI BELLO, I.; FLEET, G.; NAMGOONG, S. K.; TADANO, K.; WINCHESTER, B. Structure-activity relationship of swainsonine. Biochem. J., v. 259, p. 855861, 1989.

De BALOGH, K. I. M.; DIMANDE, A. P.; Van der LUGT, J. J.; MOLYNEUX, R. J.; NAUDÉ, T. W.; WELMAN, W. G. A lysossomal storage disease induced by Ipomoea carnea in goats in Mozambique. J. Vet. Diagn. Invest., v. 11, p. 266-273, 1999.

FUGLIUOLO, R.; NAYLOR, S.; WANG, J.; LANGENHEIM, J. H. Unusual non protein imino acid and its relationship to phenolic and nitrogenous compounds in Copaifera. Phytochemistry, v.26, p. 32553259, 1987.

GARDNER, D. R.; MOLYNEUX,R. J.; RALPHS, M. H. Analysis of swainsonine: Extraction methods, detection, and measuremet in populations of locoweeds (Oxytropis spp.). J. Agric. Food Chem., v. 49, p.4573-4580, 2001.

HARAGUCHI, M.; GÓRNIAK, S. L.; IKEDA, K.; MINAMI, Y.; KATO, A.; WATSON, A. A.; NASH, R. J.; MOLYNEUX, R. J.; ASANO, N. Alkaloidal components in the poisonous plant, Ipomoea carnea (Convolvulaceae). J. Agric. Food Chem., v.51, p. 49955000, 2003.

LORENZI, H. Ervas daninhas. In: .Plantas daninhas do Brasil: terrestres, aquáticas, parasitas, tóxicas e medicinais. 2. ed. Nova Odessa: Editora Plantarum, 1991. p. 125.

MOLYNEUX, R. J.; PAN, Y.T.; GOLDMAN, A.; TEPFER, D. A.; ELBEIN, A. D. Calystegins, a novel class of alkaloid glycosidase inhibitors. Arch. Biochem. Biophys., v. 304, p. 81-88, 1993.
MOLYNEUX, R. J.; GARDNER, D. R.; JAMES, L. F.; COLEGATE, S. M. Polyhydroxy alkaloids: Chromatographic analysis.J. Chromatogr., v. 967, p. 7578, 2002.

NEMR, A. E. Synthetic methods for the stereoisomers of swainsonine and its analogues. Tetrahedron, v. 56, p. 8579-8629, 2000.

SCHUMAHER-HENRIQUE, B.; GÓRNIAK, S. L.; DAGLI,M. L. Z.; SPINOSA, H. S. The Clinical, Biochemical, Haematological and Pathological Effects of Long-Term Administartion of Ipomoea carnea to Growing Goats. Vet. Res. Commun., v.27, n.4, p. 311-319, 2003.

SCHWARZ, A; GÓRNIAK, S. L.; BERNARDI, M. M.; DAGLI, M. L. Z.; SPINOSA, H. S. Effects of Ipomoea carnea aqueous fraction intake by dams during pregnancy on the physical and neurobehavioral development of rat offspring. Neurotoxicol. Teratol., v.25, p. 615-626, 2003.

STEGELMEIER, B. L.; MOLYNEUX, R. J.; ELBDEIN, A. D.; JAMES, L. F. The lesions of locoweed (Astragalus molissimus) swainsonine and castanospermine in rats. Vet. Pathol., v. 32, p. 289-298, 1995.

TIRKEY, K. ; YADAVA, K. P.; MANDAL, T. K. Effect of aqueous extract of Ipomoea carnea on the haematological and biochemical parameters in goats. Indian J. Animal Sci., v. 57, p. 1019-1023, 1987.

TIRKEY, K. ; YADAVA, K. P.; MANDAL, T. K.; BANERJEE, N. C. Pharmacological study of Ipomoea carnea. Indian Vet. J., v. 65, p. 206-210, 1988.

TOKARNIA, C. H.; DOBEREINER, J.; CANELLA, C. F.C. Estudo experimental sobre a toxidez do "canudo" (Ipomoea fistulosa Mart.) em ruminantes. Arq. Inst. Biol. Anim., v. 3, p. 59-71, 1960.

TOKARNIA, C. H.; DOBEREINER, J.; PEIXOTO, P. V. Plantas que causam perturbações nervosas. In: TOKARNIA, C. H. Plantas tóxicas do Brasil. Rio de Janeiro: Helianthus, 2000. p. 120-123. 
TULSIANI, D. R. P.; BROQUIST, H. P.; JAMES, L. F.; TOUSTER, $\mathrm{O}$. The similar effects of swainsonine and locoweed on tissue glycosidases and oligosaccharides of the pig indicate that the alkaloid is the principal toxin responsible for the induction of locoism. Arch. Biochem. Biophys., v. 232, p. 76-85, 1984.
WATSON, A. A.; FLEET, G. W. J.; ASANO, N.; MOLYNEUX, R. J.; NASH, R. J. Polyhydroxylated alkaloids - natural occurrence and therapeutic applications. Phytochemistry, v. 56, p. 265-295, 2001.

Recebido para publicação em 10 de julho de 2003. 